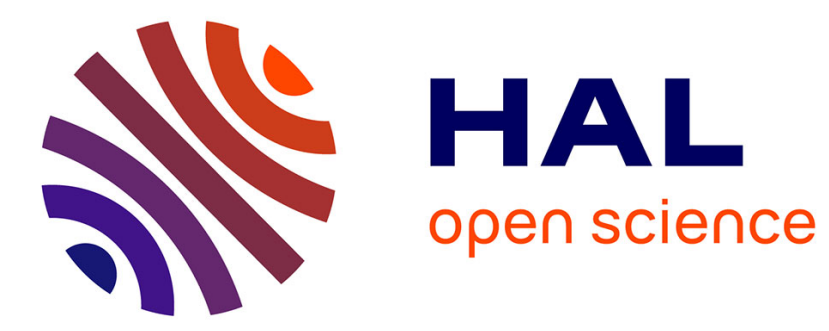

\title{
Modification of sooting tendency by magnetic effects
}

\author{
Agnes Jocher, Heinz Pitsch, Thomas Gomez, Guillaume Legros
}

\section{To cite this version:}

Agnes Jocher, Heinz Pitsch, Thomas Gomez, Guillaume Legros. Modification of sooting tendency by magnetic effects. Proceedings of the Combustion Institute, 2015, 35, pp.889 - 895 . 10.1016/j.proci.2014.05.139 . hal-01524584

\section{HAL Id: hal-01524584 https://hal.sorbonne-universite.fr/hal-01524584}

Submitted on 18 May 2017

HAL is a multi-disciplinary open access archive for the deposit and dissemination of scientific research documents, whether they are published or not. The documents may come from teaching and research institutions in France or abroad, or from public or private research centers.
L'archive ouverte pluridisciplinaire HAL, est destinée au dépôt et à la diffusion de documents scientifiques de niveau recherche, publiés ou non, émanant des établissements d'enseignement et de recherche français ou étrangers, des laboratoires publics ou privés. 


\title{
Modification of sooting tendency by magnetic effects
}

\author{
A. Jocher ${ }^{a, b}$, H. Pitsch ${ }^{b}$, T. Gomez ${ }^{a}$, G. Legros ${ }^{*, a}$
}

a Sorbonne Universités, UPMC Univ Paris 06, CNRS, UMR 7190 Institut

Jean le Rond d'Alembert, F-75005 Paris, France

b RWTH Aachen University, Institute for Combustion Technology, Aachen, Germany

${ }^{*}$ Corresponding author:

Guillaume Legros, Sorbonne Universités, UPMC Univ Paris 06, CNRS, UMR

7190 Institut Jean le Rond d'Alembert, F-75005 Paris, France, Fax: +33 130

8548 99, Email: guillaume.legros@upmc.fr

Name of Colloquium : New Technology Concepts, Reacting Flows and Fuel Technology

Alternative Colloquia $\quad$ : Laminar Flames, Soot, PAH and other large Molecules

Estimate of total length $=5368$

Method of determination : Method 2, LaTeX users, complete two-column formatted version

Main text $=3513$

References $\quad=341$

Tab. $1 \quad=88$

Fig. $1=407$

Fig. $2 \quad=99$

Fig. $3=495$

Fig. $4 \quad=280$

Fig. $5=145$ 


\title{
Modification of sooting tendency by magnetic effects
}

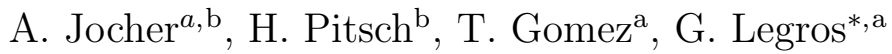 \\ ${ }^{a}$ Sorbonne Universités, UPMC Univ Paris 06, CNRS, UMR 7190 Institut Jean le Rond \\ d'Alembert, F-75005 Paris, France \\ ${ }^{b}$ RWTH Aachen University, Institute for Combustion Technology, Aachen, Germany
}

\begin{abstract}
Experimental investigations assess for the first time the influence of the gradient of the square of the magnetic flux density $\left(\nabla\left(\mathbf{B}^{2}\right)\right)$ on the soot production in a laminar axisymmetric non-premixed flame. The steady nonsmoking ethylene flame is established in a coflowing mixture, composed of oxygen and nitrogen, over a Santoro type burner. This burner is located in an electromagnet. The flame experiences different magnitudes of upward $\nabla\left(\mathbf{B}^{2}\right)$, ranging from 0 to $18.2 \mathrm{~T}^{2} / \mathrm{m}$, as well as different oxygen contents of the coflow, ranging from $21 \%$ to $50 \%$ in volume. Soot volume fraction is mapped in the flame by Laser Extinction Measurement technique. Increasing the magnitude of the $\nabla\left(\mathbf{B}^{2}\right)$ allows for the modification of soot production in the flame. This modification is enhanced by increasing oxygen content, as oxygen exhibits a relatively high paramagnetic susceptibility. Furthermore, the aforementioned modification is shown to enable the shift among similar soot concentration profiles in the flame, just as the variation of oxygen content can do. Consequently, modification of the inner flame structure by magnetic effects could contribute to the control of oxyfuel combustion.
\end{abstract}

Keywords: sooting tendency, laminar non-premixed flame, magnetic field 


\section{Introduction}

Major air pollution disasters in industrialised cities, e.g. London smog disaster in 1952, have highlighted the harmful effects of pollutant emissions by combustion devices on human health. Increased risks of cardiac arrest, pulmonary diseases, pregnancy complications and asthma are now associated with the presence of particulate matter, especially fine-particulate soot, in urban air and higher mortality rates [1-3].

Although soot formation and oxidation processes in non-premixed flames have been extensively investigated, they are not fully understood due to the numerous chemical and physical phenomena that drive them. Still, there is now a general understanding that soot production along the combustion process is the result of the following major competing processes: pyrolysis of fuel leading to the formation of soot molecular precursors, nucleation, growth of particle mass via surface reactions and coagulation, and oxidation. Oxidation mainly proceeds through the removal of carbon atoms from soot particles, by reaction with $\mathrm{O}_{2}$ and $\mathrm{OH}$ radicals $[4,5]$. While $\mathrm{O}_{2}$ is considered the most important species in the soot oxidation process, the role of $\mathrm{OH}$ radicals is more controversial. Conducting numerical simulations, Frenklach [4] stated that oxidation by $\mathrm{OH}$ radicals is relatively weak, while Kim et al. [5] showed that these radicals are highly soot-oxidising species.

Standard strategies of soot production control involve post-treatment methods, such as filters [6] and/or catalysts [7]. However, using in-situ strategies looks like an increasingly promising method. Examples are the design of new fuels [8], addition of exhaust gases to the combustion process [9], or combustion control by electrical fields [10]. Interestingly, none of these 
strategies utilises magnetic fields.

Yamada et al. [11] observed experimentally and numerically that the $\mathrm{O}_{2}$ and $\mathrm{OH}$ radicals concentration fields are highly sensitive to the gradient of the square of the magnetic flux density $\left(\nabla\left(\mathbf{B}^{2}\right)\right)$. Among the species contributing to the combustion process, $\mathrm{O}_{2}$ and $\mathrm{OH}$ indeed exhibit relatively high paramagnetic susceptibilities. The magnetic force on the species is directly proportional to the susceptibilities, but indirectly proportional to the temperature. As $\mathrm{OH}$ radicals mainly appear in the hot regions of the flame, the magnetic force on $\mathrm{OH}$ is negligible small compared to the one acting on $\mathrm{O} 2$ in the coflow. Shinoda et al. [12] studied a premixed methaneair flame and found that the magnetic force acts mainly on $\mathrm{O}_{2}$, due to its higher mass fraction. The high sensitivity of $\mathrm{OH}$ radicals on $\nabla\left(\mathbf{B}^{2}\right)$, shown by Yamada et al. [11], is mainly a result of the modified convection velocity induced by the magnetic force on $\mathrm{O}_{2}$.

While such a magnetic force can also play a significant role on the stability of non-premixed flames $[13,14]$, its influence on the sooting behaviour of nonpremixed flames has never been assessed. Consequently, the present study is a contribution to an original in-situ strategy of soot production control by magnetic fields. A steady, laminar, non-premixed ethylene flame is established over the axisymmetric burner, prescribed by Santoro et al. [15]. This configuration is selected due to the available literature about soot production, which delivers both numerical and experimental databases. A non-intrusive optical technique, based on line-of-sight attenuation measurements, provides the maps of soot volume fraction in the flames.

As a result, the modification of the inner flame structure by magnetic 
effect, is reported in terms of soot volume fraction.

\section{Experimental setup}

Figure 1 exhibits a schematic of the experimental setup.

\subsection{Burner configuration}

The non-premixed flames are established over an axisymmetric coflow burner, identical to the one described by Santoro et al. [15]. The burner's axis of symmetry is vertical. This burner was also used in previous investigations $[14,16]$. The configuration has delivered a well documented literature on the sooting behaviours of a wide range of fuels $[17,18]$.

The ethylene stream flows through a vertical axial brass duct, which has an effective diameter of injection $d_{\mathrm{F}}$, of $11 \mathrm{~mm}$. The coflowing oxidizer mixture is introduced into a concentric brass cylinder of $102 \mathrm{~mm}$ inner diameter. The oxidizer consists of a $\mathrm{O}_{2}$ and $\mathrm{N}_{2}$ mixture. Two Bronkhorst EL-FLOW mass flow controllers enable the variation of the oxygen molar content, $\mathrm{X}_{\mathrm{O}_{2}}$, in the oxidizer stream. Over the range of investigated flow rates, both fuel and oxidizer flows are steady and laminar at the height of the burner tip. Further details about the burner can be found in Ref. 14 .

In the following, the burner's axis of symmetry is $(\mathrm{O} z)$ and its origin is located at the burner tip, defining the height above the burner (HAB). The cross-stream coordinate is $r$, which is the distance from the axis of symmetry.

In order to expose the flames to fairly uniform upward $\nabla\left(\mathbf{B}^{2}\right)$, the burner tip is located $0.13 \mathrm{~m}$ below the coils' axis of symmetry.

None of the rig components is magnetic to avoid mechanical interferences. 
The rig enables the adjustment of the burner position inside the electromagnet.

\subsection{Magnetic field generation}

The electromagnet used is dedicated to combustion studies, however slightly different in size from the one described in Ref. 14. It consists of two identical coils of inner radius $\mathrm{R}=0.12 \mathrm{~m}$, that face each other, to create the magnetic field. Both coils have a common horizontal axis and are separated by a distance similar to R. An equal, constant, electrical current, I, flows through the turns that constitute each coil. Such a configuration increases the volume of the maximum magnetic field magnitude that a single coil can create and promotes the field uniformity within the system core. An iron magnetic circuit then confines the magnetic field lines.

A two-dimensional numerical simulation has been carried out to compute the magneto static field. A set of measurements by a Hall effect sensor enable the calibration of the computed fields. Details of this procedure are given in Ref. 14. As the isolevel lines in the air gap between both coils are found to be fairly horizontal, the $\nabla\left(\mathbf{B}^{2}\right)$ is directed towards the air core, i.e. upwards at the location of the burner tip. Furthermore, for any current in the electromagnet, the absolute gradient peak appears as a plateau, located at heights between $0.11 \mathrm{~m}$ and $0.14 \mathrm{~m}$ below the coils' axis. Therefore, within a cylinder

of $50 \mathrm{~mm}$ radius, whose axis is the burner's axis of symmetry (i.e. containing the coflow at the burner exit), included between the aforementioned heights, the gradient magnitudes are fairly uniform.

This academic configuration will provide clean conditions to be incor- 
porated into future numerical simulations. These will then allow further optimisation of a practical magnet design.

The level of magnetic gradient is adjusted by a power supply that delivers the current flowing into the coils up to $I_{\max }=60$ Amperes. The z-component magnitudes of the gradient together with the computed spatial fluctuations within the cylindrical domain and the current required to generate the different gradients are reported in Tab.1.

The horizontal component magnitudes of the gradients were checked to be negligible. Therefore, the gradients' direction and the burner's axis of symmetry are identical. The absence of magnetic field is called MagF 0.

\subsection{Diagnostics}

The Laser Extinction Measurement (LEM) technique, which provides a two-dimensional soot volume fraction field, has been described in details in Ref. 16. It has been shown to be capable, of providing both fine temporal and spatial resolutions. The arrangement of the optical diagnostics to perform LEM, specifically through a flame located in the electromagnet, is shown in Fig. 1. The system consists of a $100 \mathrm{~mW}$ Continuous Wave Laser operating at $645 \mathrm{~nm}(-5 /+7 \mathrm{~nm})$, a set of beam expanding optics, collection optics, and a camera. A digital pulse generator controls the occurrence and the duration of the CMOS exposure, together with the shutter opening. A frame grabber records the frames, captured by the camera, on a computer.

The Photon Focus MV1 12-bit progressive scan monochrome camera is mounted with a conventional lens, equipped with a narrow band filter centred at $645 \mathrm{~nm}( \pm 2 \mathrm{~nm})$, as well as with a band width, at one half of the trans- 
missivity maximum of $20 \mathrm{~nm}$. With this optical arrangement, the matrix of 1312 x 1082 pixels provides a spatial resolution of $50 \mu \mathrm{m}$ for the LEM projected data, over the $60 \mathrm{~mm}$ diameter area of investigation. For the current study, the frames were recorded at a frame rate of $30 \mathrm{~Hz}$ and an exposure time of $15 \mathrm{~ms}$, as the experimental conditions are such that the established non-premixed flames are very stable. Even at the flame tip, the fluctuations with time of the raw extinction measurements are weak.

As a line-of-sight technique, LEM needs to be combined with a subsequent deconvolution method, to compute the local soot volume fraction $f_{v}(r, z)$. An Onion-Peeling method is performed here, followed by a Tikhonov regularisation, which stabilised the deconvolution process [16]. This procedure allows the local extinction coefficient $\kappa_{\lambda}^{e x t}(r, z)$ to be inferred from the extinction measurements provided by the camera and to be integrated over the line-of-sight. The Mie theory then allows the distribution of $\kappa_{\lambda}^{e x t}(r, z)$ to be transformed into the soot volume fraction, assuming that particles are in the Rayleigh limit:

$$
f_{v}(r, z)=\frac{\lambda \kappa_{\lambda}^{e x t}(r, z)}{6 \pi E(m)}
$$

where $E(m)$ is a function of the complex refractive index $m$ of soot. To overcome the controversial issue of the evaluation of this parameter, together with the relative magnitude of scattering in the extinction phenomenon, we proceeded as Arana et al. [19] by adjusting $E(m)$, to reproduce the peak soot volume fraction, measured by Santoro et al. [15] at HAB $=50 \mathrm{~mm}$. The adjusted $E(m)(0.42)$ is close to the one found by Arana et al. [15] (0.38) who performed a 2D-LEM at a slightly lower wavelength $(632.8 \mathrm{~nm})$. The procedure then induces a discrepancy lower than $8 \%$ in magnitude and $5 \%$ 
in location over the remaining peaks.

\section{Results and discussion}

\subsection{Constants and parameters}

The following investigations are restricted to steady-state flames established at atmospheric pressure and constant room temperature of $295 \mathrm{~K}$.

Ethylene is chosen as fuel for its extensively documented sooting behaviour, especially on the Santoro's configuration. A single ethylene flow

rate of $3.83 \pm 0.07 \mathrm{~cm}^{3} / \mathrm{s}$ is established, corresponding to a mean fuel injection velocity of $\mathrm{V}_{\mathrm{F}}=3.98 \pm 0.09 \mathrm{~cm} / \mathrm{s}$, i.e to a fuel exit Reynolds number of $\mathrm{Re}_{\mathrm{F}}=33$. The oxidizer mixture flow rate is set at a single value of 717 $\mathrm{cm}^{3} / \mathrm{s}$, corresponding to a mean oxidizer velocity of $\mathrm{V}_{\mathrm{ox}}=8.9 \pm 0.09 \mathrm{~cm} / \mathrm{s}$. The oxidizer Reynolds number $\mathrm{Re}_{\mathrm{ox}}$ is then about 300. These flow rates are chosen so that the flames presented in this study are contained within the domain of almost uniform $\nabla\left(\mathbf{B}^{2}\right)$. Furthermore, all flames are laminar, steady, and non-smoking.

The study consists of investigating flames that are burning in oxidizer streams of four different $\mathrm{O}_{2}$ contents, i.e. $\mathrm{X}_{\mathrm{O}_{2}}=0.21,0.30,0.40$, and $0.50( \pm$ 0.01). Every flame experiences each of the three upward $\nabla\left(\mathbf{B}^{2}\right)$ reported in Tab. 1.

\subsection{Assessment of the magnetic effect}

The laser beam intensity captured over the CMOS sensor without any flame was first checked not to be influenced by any level of the magnetic field investigated. 
The influence of the three different levels of the $\nabla\left(\mathbf{B}^{2}\right)$ is first assessed on the raw integrated extinction coefficients measured inside the ethylene non-premixed flame burning into air. In this way, no modification due to the magnetic field can be attributed to the post-processing of the raw LEM data. Figure 2 shows the distributions of the integrated extinction coefficient as a function of the magnetic gradient that the flame experiences. For MagF 0 , the peak integrated extinction coefficient (0.3) is located on the flame's edge at about $\mathrm{HAB}=40 \mathrm{~mm}$. From MagF 1 to $\mathrm{MagF} 3$, the peak stays on the edge and monotonically increases in magnitude, reaching $0.32,0.36$, and 0.39, respectively. A similar increase is globally observed in the whole flame.

The oxygen molecules are attracted towards the axis of symmetry of the two iron coils, whereas diamagnetic species like $\mathrm{N}_{2}$ or $\mathrm{C}_{2} \mathrm{H}_{4}$ are rejected by the increasing magnetic field [21]. Nevertheless, the absolute value of the oxygen magnetic susceptibility per unit weight can be assumed several times larger than those of diamagnetic gases [20]. Consequently, the main influence of the magnetic field on the non-premixed flame is expected to be caused by the oxygen concentration field. The flame is here submitted to an upward gradient of the square of the magnetic flux density. As explained by Yamaguchi and Tanimoto [20], the resulting thermo-magneto convection is therefore opposed to buoyancy. For relatively long flames, buoyancy plays an important role. However with increasing $\nabla\left(\mathbf{B}^{2}\right)$, the thermo-magneto convection is enhanced. Consequently the global residence time inside the flame is increased with increasing $\nabla\left(\mathbf{B}^{2}\right)$. Furthermore, the thermo-magneto convection will also reduce the velocity of the fresh oxidizer flow. The shear stress between the oxidizer and fuel flow will therefore be weakened. Both 
effects then promote soot formation. Indeed, higher integrated extinction coefficients are reported both on the edge and on the axis of the flame when the magnitude of the upward magnetic gradient is increased.

At constant fuel and oxidizer flow rates of $3.83 \mathrm{~cm}^{3} / \mathrm{s}$ and $717 \mathrm{~cm}^{3} / \mathrm{s}$, respectively, the oxygen content in the oxidizer stream is varied from $21 \%$ O2 (air) to $50 \%$. Figure 3 exhibits the distributions of the soot volume fraction for different values of the magnetic gradient and for different oxygen contents. To provide comparable maps, every distribution of the soot volume fraction is shown in a non-dimensional form, the reference value being the peak $f_{v, \max }$ obtained among the distributions at a given oxygen content. These reference values are reported on the right of every row.

At any magnetic gradient, when increasing the $\mathrm{O}_{2}$ content, the flame length is reduced due to enhanced transport of oxygen towards the fuel side of the flame. In Fig.3, this effect is somewhat less obvious, due to the variable scale of the $z$-axis. The peak soot volume fraction is then increased with increasing oxygen content since in hotter and smaller flames, the soot formation rate is hastened on the rich side of the flame.

At a constant $\mathrm{O}_{2}$ content, the influence of the magnetic gradient on the non-premixed flame is significant but ambiguous. For $\mathrm{X}_{\mathrm{O}_{2}}=21 \%$, the peak soot volume fraction is increased and shifted towards the flame axis when increasing the magnetic gradient. However, for higher $\mathrm{X}_{\mathrm{O}_{2}}$, the peak soot volume fraction is shifted away from the flame axis and now decreases in magnitude with increased magnetic gradient. This is in agreement with the longer characteristic residence time mentioned above. Yet, this decrease is balanced as the soot layer also spreads slightly over when increasing the 
magnetic gradient.

To further elucidate these observations, net soot production is now characterised by the integrated soot volume fraction $F_{v}(z)$ defined as follows:

$$
F_{v}(z)=\frac{1}{\pi\left(d_{F} / 2\right)^{2}} \int_{0}^{d_{F} / 2} 2 \pi r f_{v}(r, z) d r
$$

$F_{v}(z)$ appears as an evaluation of the actual soot load at a given HAB in the flame. Its maximum value $F_{v, \max }$ can therefore be considered a relevant characteristics of the competition between soot formation and oxidation along the globally upward trajectories that particles experience. For this reason, the height $z_{\max }$ at which $F_{v, \max }$ occurs is also a characteristic length of the soot formation and oxidation processes. Figure 4 then exhibits the profiles of non-dimensional $F_{v} / F_{v, \max }$ as a function of non-dimensional height $z / z_{\max }$. For every oxygen content, a specific $F_{v, \max }$ is defined as the maximum value of $F_{v}$ for MagF 0 and the specific $z_{\max }$ is the height where $F_{v, \max }$ is reached. For $\mathrm{X}_{\mathrm{O}_{2}}=21 \%$, the upper parts of the profiles are missing because the soot volume fraction fields are not fully encompassed into the laser beam section. However, the central parts around $F_{v, \max }$ are well characterised.

At a given magnetic gradient, the profiles for the different oxygen contents investigated look very similar, further supporting $z_{\max }$ and $F_{v, \max }$ as characteristic quantities of soot related processes into these non-premixed flames. Per se, this finding is not marginal. Among others, Roper [22] showed that non-premixed flame sheets are similar. However, soot particles contribute to phenomena that are essentially volumetric due to the relatively long characteristic times of formation and oxidation. The flame sheet assumption can then be considered all the more questionable when the flame is sooty. Nonetheless, the quantity $F_{v}(z)$ appears here to decently follow a similarity 
law.

At any oxygen content, the effect of the magnetic gradient on the net soot production does not reverse as the aforementioned ambiguous trends may have led to conclude. Indeed, increasing the magnetic gradient monotonically enhances soot production for every oxygen content. Similar trends have been reported in non-buoyant non-premixed flames [23], which further supports the above reasoning about the balance between buoyancy and thermomagneto convection. Interestingly, when increasing the oxygen content, the soot production enhancement by the magnetic gradient is emphasised and can be considered significant. Therefore, the modification of soot production by magnetic gradients could constitute a relevant strategy of reacting flows control, especially in the field of oxyfuel combustion where oxygen content is relatively high.

\subsection{Magnetic scaling of soot production}

As an illustration of such a strategy, we investigated the potential to scale the soot production by the magnetic gradient. To address a practical concern, we sought for reproducing the profile of non-dimensional integrated soot volume fraction experimentally measured for Mag $0(I=0)$ and $\mathrm{X}_{\mathrm{O}_{2}}=$ $50 \%$ with a lower oxygen content, i.e. $\mathrm{X}_{\mathrm{O}_{2}}=30 \%$, and with the help of the magnetic gradient. This strategy would potentially lead to lower the oxygen flow rate in an oxyfuel combustion device.

To this end, the database composed of the experimental $z / z_{\max }(0.5 \leq$ $\left.z / z_{\max } \leq 1.2\right), F_{v} / F_{v, \max }, \mathrm{X}_{\mathrm{O}_{2}}$, and $I / I_{\max }$ was approximated by an interpo- 
lation function $G_{\text {interp }}$, as schematically represented by Eq.(3):

$$
F_{v} / F_{v, \max }=G_{\text {interp }}\left(z / z_{\max }, X_{\mathrm{O}_{2}}, I / I_{\max }\right)
$$

$G_{\text {interp }}$ was finally a second-order polynomial which was found to adequately model the experimental $F_{v} / F_{v, \max }$ with an error range lower than 3 $\%$. The ten coefficients of this polynomial were determined using a trustregion-reflective algorithm [24] that minimises the least-squares between the results of Eq.(3) and the set of experimental $F_{v} / F_{v, \max }$.

We then selected a specific $z / z_{\max }$, i.e. 0.87 , into the experimental profile for $\mathrm{X}_{\mathrm{O}_{2}}=50 \%$ and MagF 0. At this non-dimensional height, $F_{v} / F_{v, \max }$ is equal to 0.97. Intending to reproduce the profile for $\mathrm{X}_{\mathrm{O}_{2}}=50 \%$ and MagF 0, we solved Eq.(3) for $I / I_{\max }$ with $z / z_{\max }=0.87, F_{v} / F_{v, \max }=0.97$, and $\mathrm{X}_{\mathrm{O}_{2}}$ $=30 \%$. The computed current was $I / I_{\max }=0.167$, i.e. $I=10.0$ amperes. This current induces a magnetic gradient of about $1.1 \mathrm{~T}^{2} / \mathrm{m}$.

We finally established the flame for $\mathrm{X}_{\mathrm{O}_{2}}=30 \%$ and $I=10.0$ Amperes and measured the soot volume fraction field. Figure 5 exhibits the targeted profile $F_{v} / F_{v, \max }$ measured for $\mathrm{X}_{\mathrm{O}_{2}}=50 \%$ and $I=0$, together with the one measured for $\mathrm{X}_{\mathrm{O}_{2}}=30 \%$ and $I=10.0$ Amperes. The close up view in the upper right corner shows that the specific point targeted is fairly reproduced in the flame for $\mathrm{X}_{\mathrm{O}_{2}}=30 \%$ and $I=10.0$ Amperes. This strategy assessment looks here especially relevant in the lower part of the profiles, i.e. in a region where soot formation dominates soot oxidation. Downstream $z / z_{\max }=1$, soot oxidation starts prevailing, potentially due to higher levels of $\mathrm{OH}$ radicals [5]. Yet, these radicals also exhibit relatively high magnetic susceptibility. Therefore, a sophisticated coupling between the transport of these radicals and the thermo-magneto convection conveying oxygen may reveals, damaging 
the similarity of the $F_{v} / F_{v, \max }$ profiles.

\section{Conclusion}

The present study may be considered an original and significant step towards the identification of a possible strategy that would enable the magnetic control of soot production in a non-premixed flame. The original experimental setup included the coflow burner prescribed by Santoro, together with an optical arrangement that allows the measurements of two-dimensional soot volume fraction fields in the flame. Thus, the influence of the magnitude of an upward magnetic gradient on the soot production inside the ethylene non-premixed flame was investigated.

Increasing the magnitude of the magnetic gradient allowed the modification of soot production in the flame. This modification is enhanced with increasing oxygen content, as oxygen exhibits a relatively high paramagnetic susceptibility. Furthermore, this modification was shown to enable the shift among similar profiles of soot concentration in the flame, as the variation of oxygen content does.

This latest finding may drive further optimisation of the strategy. CO2 addition to the coflowing air will induce a decrease of the adiabatic flame temperature due to the higher specific heat of $\mathrm{CO}_{2}$ compared to that $\mathrm{N}_{2}$. Since the Curie law predicts a magnetic susceptibility that is inversely proportional to the temperature, this should globally enhance the magnetic effect. For this reason, the scope of the strategy could be extended to the field of oxyfuel combustion.

While reversing the magnetic field itself has no effect on $\nabla\left(\mathbf{B}^{2}\right)$ and hence 
on the soot volume fraction maps, a reduction of soot production might be possible when shifting the burner to the upper core of the electromagnet to

meet downwards $\nabla\left(\mathbf{B}^{2}\right)$. For these further investigations, the whole setup will be carefully modified.

\section{Acknowledgments}

The authors acknowledge the Université franco-allemande/Deutsch-Französische Hochschule for their financial support. The authors feel very grateful to M. Kashif, J. Bonnety, H. Dutilleul, and J.M. Citerne for their technical support. 
[1] M. Patricia Sierra-Vargas, L.M. Teran, Respirology 17 (2012) 1031-1038.

[2] P.T. O' Shaughnessy, Environ. Sci.: Processes Impacts 15 (2013) 49-62.

[3] M.R. Heal, P. Kumar, R.M. Harrison, Chem. Soc. Rev. 41 (2012) 6606-6630.

[4] M. Frenklach, Phys. Chem. Chem. Phys. 4 (2002) 2028-2037.

[5] C.M. Kim, A.M. El-Leathy, F. Xu, G.M. Faeth, Comb. Flame 136 (2004) 191-207.

[6] P. Tandon, A. Heibel, J. Whitmore, N. Kekre, K. Chithapragada, Chem. Eng. Sci. 65 (2010) 4751-4760.

[7] K. Leistner, A. Nicolle, P. Da Costa, Energy \& Fuels 26 (2012) 6091-6097.

[8] R.J.H. Klein-Douwel, A.J. Donkerbroek, A.P. van Vliet, M.D. Boot, L.M.T. Somers, R.S.G. Baert, N.J. Dam, J.J. ter Meulen, Proc. Combust. Inst. 32 (2009) 2817-2825.

[9] O. Angrill, H. Geitlinger, T. Streibel, R. Suntz, H. Bockhorn, Proc. Combust. Inst. 28 (2000) 2643-2649.

[10] Y. Wang, G.J. Nathan, Z.T. Alwahabi, K.D. King, K. Ho, Q. Yao, Comb. Flame 157 (2010) 1308-1315.

[11] E. Yamada, M. Shinoda, H. Yamashita, K. Kitagawa, Comb. Flame 135 (2003) 365379 .

[12] M. Shinoda, E. Yamada, T. Kajimoto, H. Yamashita, K. Kitagawa, Proc. Combust. Inst. 30 (2005) 277-284.

[13] V. Gilard, P. Gillon, J.-N. Blanchard, B. Sahr, Combust. Sci. Technol. 180 (2008) 1920-1935.

[14] G. Legros, T. Gomez, M. Fessard, T. Gouache, T. Ader, P. Guibert, P. Sagaut, J.L. Torero, Proc. Combust. Inst. 33 (2011) 1095-1103.

[15] R.J. Santoro, H.G. Semerjian, R.A. Dobbins, Combust. Flame 51 (1983) 203-218.

[16] M. Kashif, J. Bonnety, P. Guibert, C. Morin, G. Legros, Opt. Express 20 (2012) $28742-28751$.

[17] F. Liu, G. Hongsheng, G.J. Smallwood, Ö.L. Gülder, Combust. Theory Modelling 7 (2003) 301-315.

[18] C.S. McEnally, L.D. Pfefferle, Environ. Sci. Technol. 45 (2011) 2498-2503.

[19] C.P. Arana, M. Pontoni, S. Sen, I.K. Puri, Comb. Flame 138 (2004) 362-372.

[20] M. Yamaguchi, Y. Tanimoto, Magneto-Science, Springer Berlin Heidelberg (Germany), 2006, p. 100.

[21] N. Wakayama, Chemical Physics Letters 185 (1991) 449-451. 
[22] F.G. Roper, Comb. Flame 29 (1977) 219-226.

[23] G. Legros, A. Fuentes, S. Rouvreau, P. Joulain, B. Porterie, J.L. Torero, Proc. Combust. Inst. 32 (2009) 2461-2470.

[24] T.F. Coleman, Y.Y. Li, SIAM J. Optimiz. 6 (1996) 418-445. 
Table 1: $\nabla\left(\mathbf{B}^{2}\right)$ magnitudes.

Magnetic field MagF $1 \quad$ MagF $2 \quad$ MagF 3

$\begin{array}{llll}\text { Average peak }\left(\mathrm{T}^{2} / \mathrm{m}\right) & 1.8 & 7.1 & 18.2\end{array}$

Spatial fluctuation $\left(\mathrm{T}^{2} / \mathrm{m}\right) \quad \pm 0.01 \quad \pm 0.1 \quad \pm 0.3$

$\begin{array}{llll}\text { Current }(\mathrm{A}) & 13 & 26 & 60\end{array}$



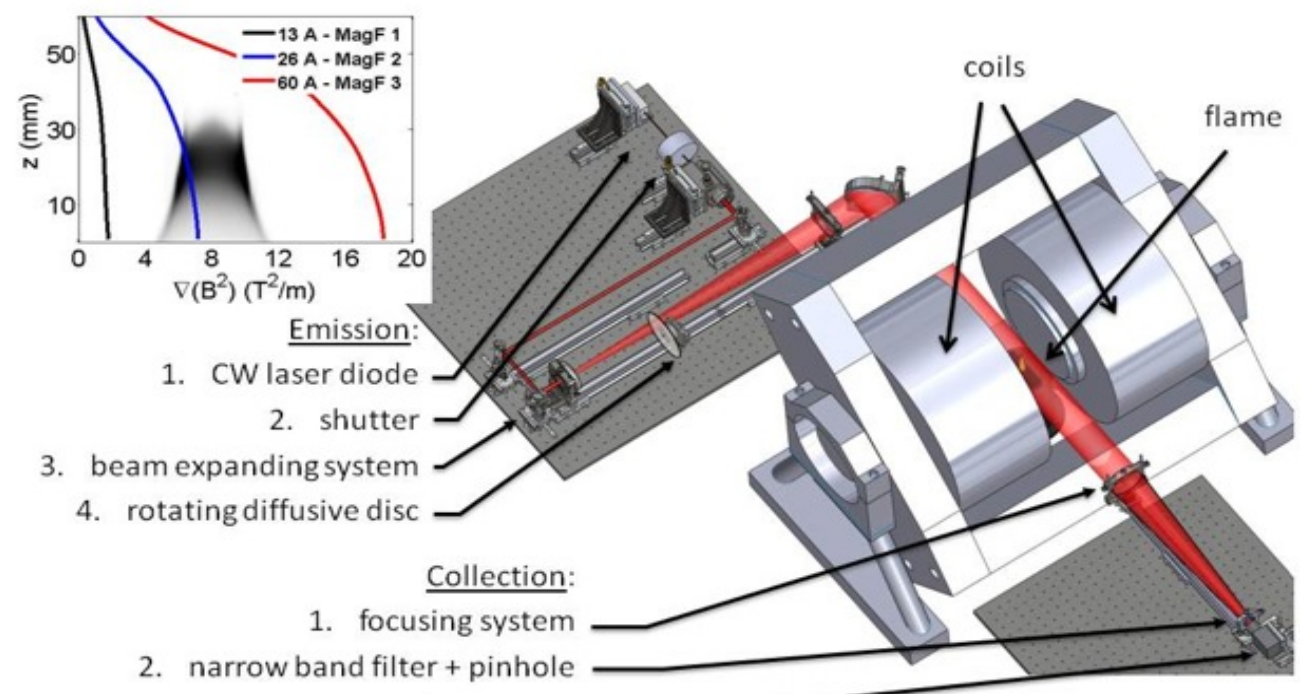

2. narrow band filter + pinhole

3. camera

Figure 1: Schematic view of the experimental setup. This allows soot volume fraction measurements in an axisymmetric ethylene non-premixed flame experiencing different magnitudes of $\nabla\left(\mathbf{B}^{2}\right)$. The insert in the upper left corner exhibits the different profiles of $\nabla\left(\mathbf{B}^{2}\right)$ as a function of HAB. As an illustration, the flame established for $\mathrm{X}_{\mathrm{O}_{2}}=50 \%$ and $\mathrm{MagF}$ 0 is shown in reversed intensity scale. 


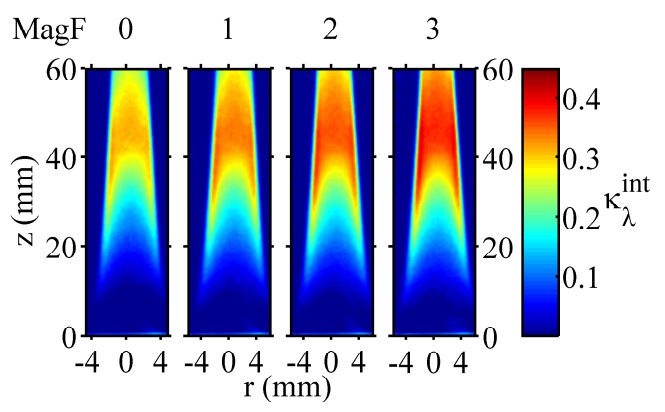

Figure 2: Maps of the raw integrated extinction coefficient $\kappa_{\lambda}^{\text {int }}$ for increasing $\nabla\left(\mathbf{B}^{2}\right)$ magnitudes, starting from MagF 0 to MagF 3. The ethylene non-premixed flame burns here in air. 


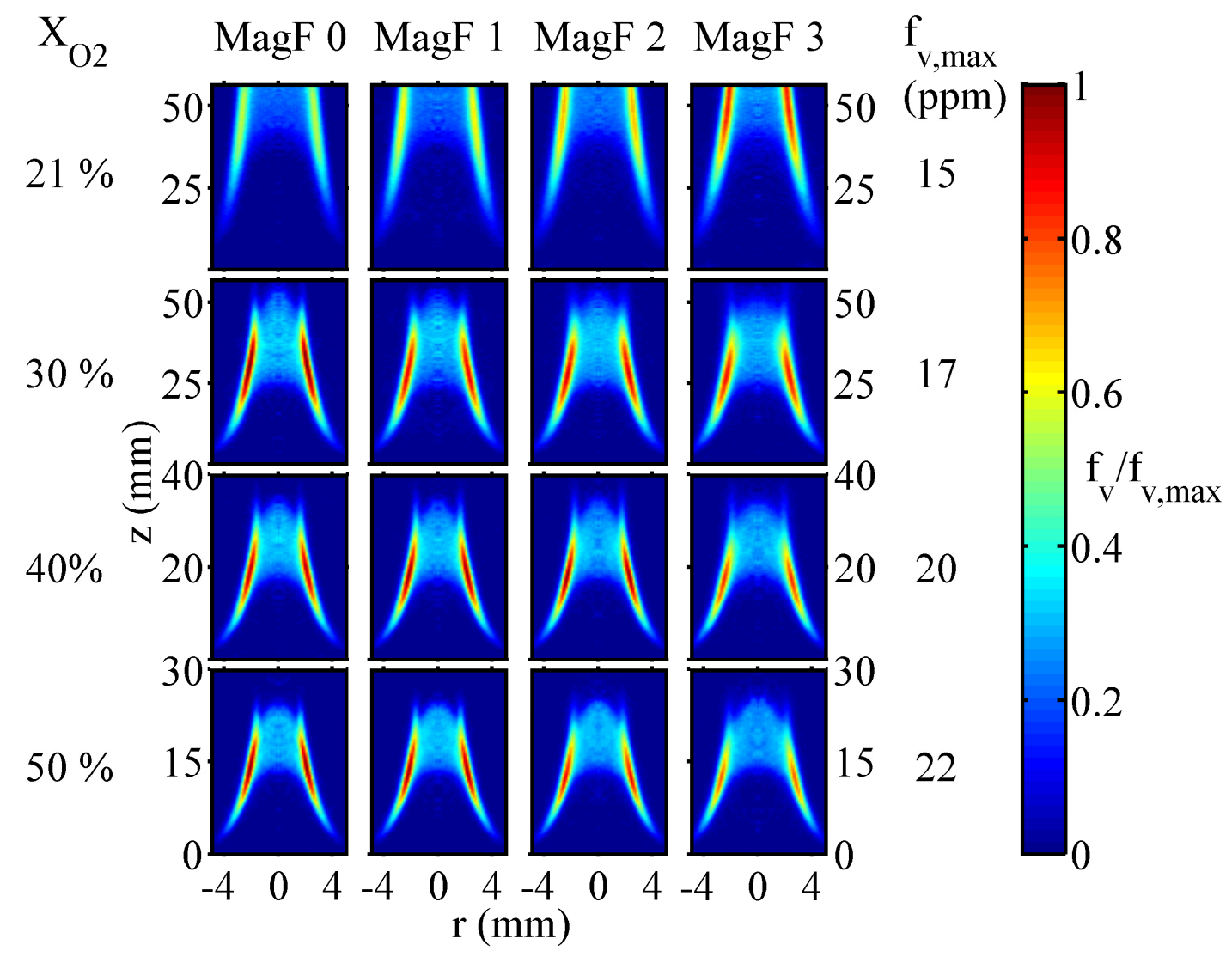

Figure 3: Non-dimensional soot volume fraction maps for increasing magnetic gradient from the left to the right, and for increasing oxygen content in the oxidizer stream from the top the the bottom. For every oxygen content, the reference $f_{v, \max }$ is reported on the right of the corresponding row. 


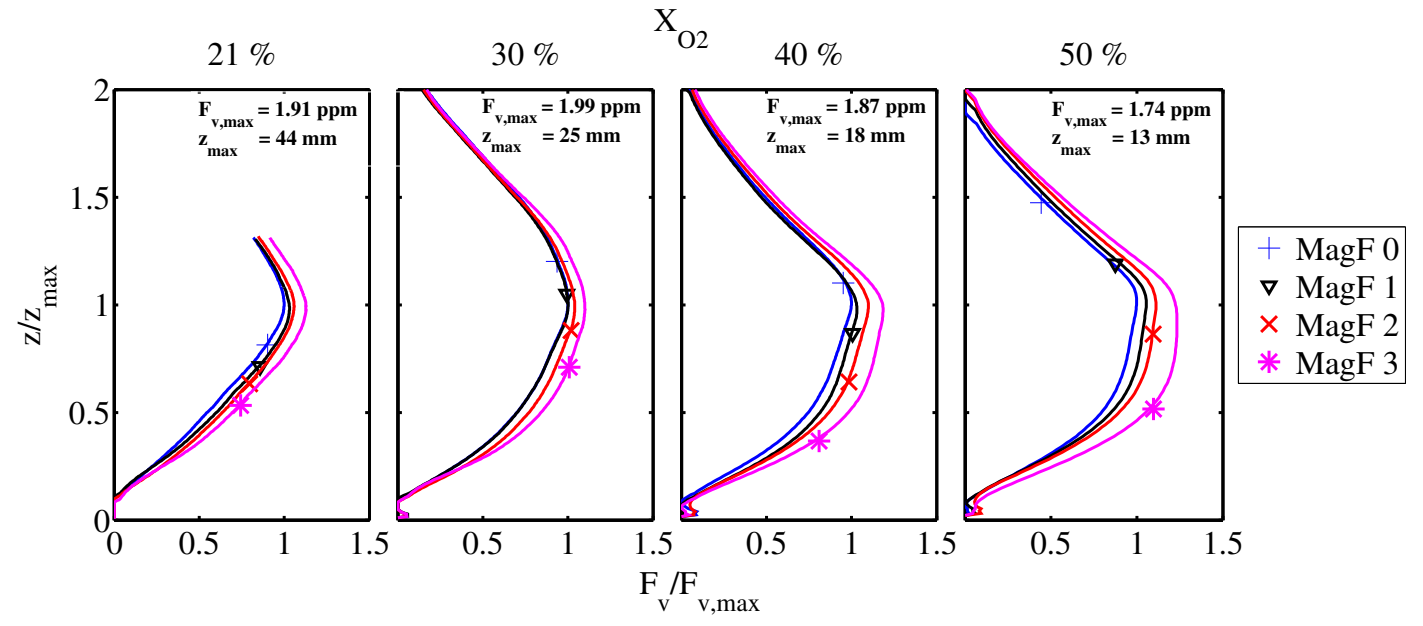

Figure 4: Profiles as a function of non-dimensional height $z / z_{\max }$ of non-dimensional integrated soot volume fraction $F_{v} / F_{v, \max }$ for different $\nabla\left(\mathbf{B}^{2}\right)$ magnitudes, starting from MagF 0 to MagF 3, and for different oxygen contents. 


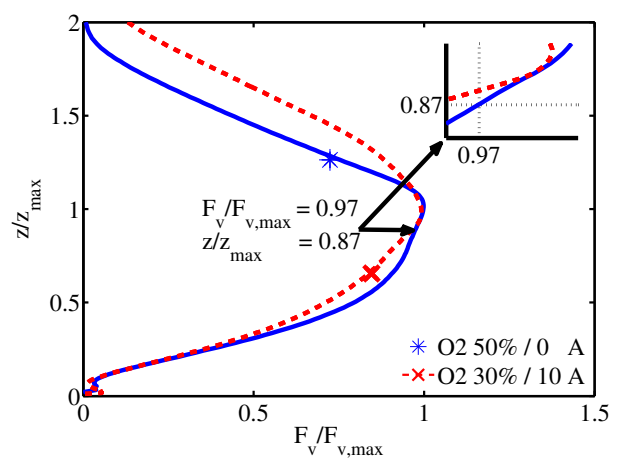

Figure 5: Profiles as a function of non-dimensional height $z / z_{\max }$ and non-dimensional integrated soot volume fraction $F_{v} / F_{v, \max }$. The experimental profile for $\mathrm{X}_{\mathrm{O}_{2}}=30 \%$ and $I=10.0$ Amperes intends to reproduce the experimental profile for $\mathrm{X}_{O_{2}}=50 \%$ and $I=$ 0 Ampere at the specific location $z / z_{\max }=0.87$ and $F_{v} / F_{v, \max }=0.97$. The matching between both profiles around this location is shown in the close up view in the insert. 